OPEN ACCESS

Edited by:

Alberto Forte

Sapienza University of Rome, Italy

Reviewed by:

Lars de Vroege

GGz Breburg, Netherlands

Donna Thomas,

Louisiana Tech University,

United States

*Correspondence:

Marie Vazquez Morgan

marie.vazquez@/suhs.edu

Specialty section:

This article was submitted to

Public Mental Health,

a section of the journal

Frontiers in Psychiatry

Received: 18 October 2021 Accepted: 06 December 2021 Published: 22 December 2021

Citation:

Vazquez Morgan M (2021) Promoting Student Wellness and Self-Care

During COVID 19: The Role of Institutional Wellness.

Front. Psychiatry 12:797355.

doi: 10.3389/fpsyt.2021.797355

\section{Promoting Student Wellness and Self-Care During COVID 19: The Role of Institutional Wellness}

\author{
Marie Vazquez Morgan* \\ Louisiana State University Health Shreveport, Shreveport, LA, United States
}

Stress and burnout are serious and growing threats to the mental health of medical trainees. Recent estimates of burnout in medical students and residents are quite high, with more than half displaying signs of stress, anxiety and depression. The COVID-19 pandemic has only heightened the state of poor mental health in these student populations. It is the position of LSU Health Shreveport Office of Institutional Wellness that a critical need exists for academic institutions to evaluate challenges to self-care and wellbeing in medical trainees. Such evaluations may pave the way for the development of effective institutional wellness initiatives and strategies, with the goal of reducing barriers to self-care to promote better mental and physical health, and facilitate improved quality of life in medical students and residents.

Keywords: COVID-19, medical students and residents, self-care, burnout, poor mental health

\section{INTRODUCTION}

The COVID-19 pandemic created widespread stress and anxiety in the US population. Social distancing, increasing joblessness and limited access to mental health services, created an increased mental health burden during and beyond the pandemic (1-7). Student mental health has been a growing issue in academia. Even prior to the pandemic, national data sources displayed increased rates of burnout, depression, eating disorders, alcohol abuse and self harm in student populations (8). According to the 2019 Annual Report of the Center for Collegiate Mental Health, anxiety continued to be a widespread problem with numbers as high as $62.7 \%$ (9). The pandemic has only worsened students' mental health, with studies reporting increases in alcohol dependence, burnout, depression, suicidality, and fatigue (10-12). Studies have also displayed medical trainees may also be less likely to seek treatment due to the stigma of mental illness, and the perception of not being able to handle the rigors of medical training $(10,13)$.

Students of color (SOC) have been disproportionately impacted during the pandemic, displaying poorer outcomes with COVID-19 as well as increased rates of anxiety and depression $(12,14)$. Poorer mental health in SOC is often due to underlying social inequities, such as food and housing insecurity, racial and ethnic discrimination, and decreased access to technology required for online learning $(12,14)$.

One tactic to promote wellness and reduce stress during the rigors of medical training is to engage in self-care activities $(15,16)$. These activities should address the varied dimensions of wellness including physical activity, socialization, proper nutrition and stress management (17). However, the demanding pace of medical training often makes it a challenge for students to prioritize the time required for self-care activities (18). 
Ayala et al., in a 2017 study on self-care, found "a robust inverse relationship between perceived stress and medical students' quality of life" (17). The authors concluded that their findings suggested self-care may be an effective strategy for reducing the effects of stress and burnout in medical students.

In addition, early application of self-care during medical training may promote sustainable healthy behaviors postgraduation (19). Sustainability of self-care is important postgraduation, as the literature reports that healthcare workers, including physicians, have experienced impaired mental health during the COVID-19 pandemic (20, 21). Protection of the mental health of physicians and other healthcare workers has been labeled as important by the World Health Organization in 2020 (22).

Due to the increased prevalence of mental health impairments in medical students and residents, investigating the relationships between poor mental health and the challenges faced in initiating self-care may assist academic institutions to better understand these issues and offer more effective wellness initiatives that address the barriers currently faced by trainees.

\section{POSITION}

It is the position of LSU Health Shreveport, Office of Institutional Wellness that medical student and resident burnout is a significant issue, and lack of self-care is often overlooked as a contributing factor. A pressing need exists to evaluate the role of self-care to increase overall wellbeing and to combat burnout and stress during medical training. LSU Health Shreveport is committed to reducing student burnout by assessing and addressing the issues causing and fueling poor mental student health and by providing an academic environment that values wellness and self-care.

\section{DISCUSSION}

Medical trainees commonly experience stress and burnout, and poor mental health greatly contributes to decreases in their quality of life $(9,11,13,23)$. Researchers and wellness advocates maintain not practicing self-care during medical training is detrimental to mental and physical health and further contributes to increased risk of burnout and stress (15-17).

Promotion and facilitation of self-care during medical training is vital in order to promote long-term lifestyle modification that is sustainable post-graduation. This is important, as the literature displays that the mental health of medical professionals, not just medical students, has been challenged during the pandemic $(20,21,23,24)$. Further, poor mental health has been shown to be exacerbated when medical professionals feel unsupported by administration regarding wellbeing initiatives (20).

It is vital that academic institutions provide an organizational culture of wellbeing by assessing challenges to self-care and by implementing institutional strategies and measures that encourage sound mental and physical health. Such initiatives can include online wellness platforms, support groups, increased access to mental health services, classes on yoga, mindfulness, sleep health, time management, nutrition and fitness, as well as longitudinal wellness index surveys (25-27).

To facilitate self-care, virtual/in person classes on the importance of stress management, nutrition, sleep health and meditation can be incorporated into the matriculation process. Faculty and community wellness advocates can facilitate these classes during lunch hours or protected time allotted for selfcare. Offering these types of classes during medical training is vital, as trainees whom increase their knowledge and practice selfcare can more effectively weather school-related stress and build better resilience (28).

Longitudinal wellness index surveys can be used effectively to monitor stress and burnout $(23,25)$. These surveys provide complete anonymity to remove the fear of self-assessing, and trainees can compare their wellbeing measures to peers' and national averages. They can also gain access to local and national resources on stress/resiliency, work-life integration, and resources to combat or prevent alcohol/substance abuse to help improve their wellbeing. These surveys allow for continuous measurement through periodic reassessments in order for trainees to track their progress over time. They can also allow academic institutions to assess periods of high stress in trainees, to allow for better planning and scheduling of self-care activities.

In addition, addressing barriers to self-care is vital to ensure sound participation $(18,29)$. Due to the demanding pace of medical education and training, students and residents may perceive wellness activities as an encroachment on their time, which in turn may inadvertently increase stress levels and decrease their participation (18). Perceived loss of time from participating in wellness activities can be lessened through protected time for self-care activities. It can also be mitigated by incidental physical activity challenges. Incidental activity is defined as activity performed in small increments over the course of day. It tends to be less structured than a planned exercise session, and can occur in many forms (i.e. skipping the elevator and taking the stairs, walking during lunch or spending more time standing than sitting during the day). These activity challenges are easy to employ on a daily basis and students/residents may feel less threatened by them as they can be performed without further constraints on their time. Another way to address this barrier is to offer online wellness platforms that provide exercise and wellness classes on demand, so medical trainees can take classes when it best fits their schedules. Finally, sponsorships to local community gyms where trainees can meet to partake in team sporting tournaments and events can assist with increasing physical activity with the added benefit of socialization with peers.

Due to the COVID-19 pandemic, there has been an increased need for student mental health interventions, however due to time restrictive schedules, students and residents may not seek out treatment for poor mental health. To combat this challenge, behavioral health/counseling centers can add flexible hours (after hours or weekends), and provide a 24/7 crises management hotline to assist with emergent mental health issues.

Further, it is important to remember that the COVID-19 pandemic has not affected trainees equally, and has exacerbated the distinct mental health issues faced by SOC, lesbian, gay, 
bisexual, transgender, queer (LGBTQ) students, and students that are economically disadvantaged $(12,14)$. Academic institutional leadership needs to be aware of cultural issues that can impact both physical and mental wellbeing in underrepresented minority students and residents. Culturally based stigmas surrounding mental health care, an inherent distrust of the health care system or a lack of providers from diverse racial/ethnic backgrounds can be barriers to seeking out treatment. Providing counselors from diverse genders and backgrounds can assist with reducing these barriers and facilitate culturally competent care to all students. Further, staff should receive training on implicit bias, cultural awareness, sensitivity and competence. Cultural competence training is utilized to "increase therapists' awareness of their own assumptions, values, and biases and knowledge of research, assessment, and practice" (30). Such training can facilitate more equitable care and improve outcomes, particularly to students from culturally and linguistically diverse backgrounds $(30,31)$.

\section{CONCLUSIONS}

Physical and emotional wellbeing are key to academic success in medical education. However, medical students and residents face poor mental health due to the rigors of their training and decreased ability to practice self-care. Research studies report medical trainees and healthcare professionals are at increased risk for poor nutrition, reduced sleep health, depression, and suicide. This is especially true in underrepresented students and residents. These conditions have become even more prevalent

\section{REFERENCES}

1. Brooks SK, Webster RK, Smith LE, Woodland L, Wessely S, Greenberg N, et al. (2020). The psychological impact of quarantine and how to reduce it: rapid review of the evidence. Lancet. 395:912-20. doi: 10.1016/S0140-6736(20)30460-8

2. Cénat JM, Blais-Rochette C, Kokou-Kpolou CK, Noorishad PG, Mukunzi JN, McIntee SE, et al. Prevalence of symptoms of depression, anxiety, insomnia, posttraumatic stress disorder, and psychological distress among populations affected by the COVID-19 pandemic: a systematic review and meta-analysis. Psychiatry Res. (2021) 295:113599. doi: 10.1016/j.psychres.2020.113599

3. Li S, Wang Y, Xue J, Zhao N, Zhu T. The impact of COVID-19 epidemic declaration on psychological consequences: a study of active Weibo users. Int J Environ Res Public Health. (2020) 17:2032. doi: 10.3390/ijerph17062032

4. Perrin PC, McCabe OL, Everly GS, Links JM. Preparing for an influenza pandemic: mental health considerations. Prehosp Disaster Med. (2009) 24:223-30. doi: 10.1017/S1049023X00006853

5. Tsamakis K, Tsiptsios D, Ouranidis A, Mueller C, Schizas D, Terniotis C, et al. COVID-19 and its consequences on mental health (Review). Exp Ther Med. (2021) 21:244. doi: 10.3892/etm.2021.9675

6. Usher K, Bhullar N, Jackson D. Life in the pandemic: social isolation and mental health. J Clin Nurs. (2020) 29:2756-7. doi: 10.1111/jocn.15290

7. Yang H, Ma J. How an epidemic outbreak impacts happiness: Factors that worsen (vs. protect) emotional well-being during the coronavirus pandemic. Psychiatry Res. (2020) 289:113045. doi: 10.1016/j.psychres.2020.113045

8. Blanco C, Okuda M, Wright C, Hasin DS, Grant BF, Liu SM, et al. Mental health of college students and their non-college-attending peers: results from the national epidemiologic study on alcohol and related conditions. Arch Gen Psychiatry. (2008) 65:1429-37. doi: 10.1001/archpsyc.65.12.1429 after COVID-19. Self-care has been shown to attenuate poor mental health and stress, however due to time constraints during medical training, few seek out or practice wellness activities. Increasing opportunities for medical trainees to participate in self-care activities during their training, can assist them in developing strong values for self-care, and become better wellness advocates to future patients. A fundamental shift recognizing the essential role of self-care is needed in order to address the epidemic of stress and burnout among medical trainees. Academic institutions must also understand and address the barriers students and residents face in regards to practicing self-care and wellbeing, and emphasize initiatives that address burnout-related issues and provide beneficial, culturally competent resources. Helping students and residents recognize the importance self-care and wellness during their medical training assists them in developing resilience, which will help them deal with stress more effectively during their matriculation and post-graduation, and improve their quality of life.

\section{DATA AVAILABILITY STATEMENT}

The original contributions presented in the study are included in the article/supplementary material, further inquiries can be directed to the corresponding author/s.

\section{AUTHOR CONTRIBUTIONS}

The author confirms being the sole contributor of this work and has approved it for publication.
9. annual report. Center for Collegiate Mental Health. University Park, PA: Penn State University. (2020). Available online at: https://ccmh.memberclicks.net/ assets/docs/2019-CCMH-Annual-Report_3.17.20.pdf

10. Liu CH, Stevens C, Wong SHM, Yasui M, Chen JA. The prevalence and predictors of mental health diagnoses and suicide among US college students: Implications for addressing disparities in service use. Depress Anxiety. (2019) 36:8-17. doi: 10.1002/da.22830

11. Nagy GA, Fang CM, Hish AJ, Kelly L, Nicchitta CV, Dzirasa K, et al. Burnout and Mental Health Problems in Biomedical Doctoral Students. CBE Life Sci Educ. (2019) 18:ar27. doi: 10.1187/cbe.18-09-0198

12. Molock SD, Parchem B. The impact of COVID-19 on college students from communities of color. J Am College Health. (2021) 27:1-7. doi: 10.1080/07448481.2020.1865380. [Epub ahead of print].

13. Rotenstein LS, Ramos MA, Torre M, Segal JB, Peluso MJ, Guille C, et al. Prevalence of depression, depressive symptoms, and suicidal ideation among medical students: a systematic review and metaanalysis. JAMA. (2016) 316:2214-36. doi: 10.1001/jama.2016.1 7324

14. Godoy M, Wood D. What Do Coronavirus Racial Disparities Look Like State By State? Available online at: https://www.npr.org/sections/health-shots/ 2020/05/30/865413079/what-do-coronavirus-racial-disparities-look-likestate-by-state. 23 June 2021.

15. Gordon JS. Mind-body skills groups for medical students: reducing stress, enhancing commitment, and promoting patient-centered care. BMC Med. (2014) 14:198. doi: 10.1186/1472-6920-14-198

16. Richards KC, Campenni CE, Muse-Burke JL. Self-care and wellbeing in mental health professionals: The mediating effects of self-awareness and mindfulness. J Ment Health Couns. (2010) 32:247. doi: 10.17744/mehc.32.3.0n31v88304423806 
17. Ayala EE, Omorodion AM, Nmecha D, Winseman JS, Mason HRC. What do medical students do for self-care? A student-centered approach to wellbeing. Teach Learn Med. (2017) 3:237-46. doi: 10.1080/10401334.2016.1271334

18. Dajani T, Bryant V, Sackett D, Allgood J. Your Wellness Program Is Interfering With My Well-Being: Reducing the Unintended Consequences of Wellness Initiatives in Undergraduate Medical Education. MedEdPublish. (2021) 10:146. doi: 10.15694/mep.2021.000146.1

19. Matheson KM, Barrett T, Landine J, McLuckie A, Soh NL, Walter G. Experiences of psychological distress and sources of stress and support during medical training: a survey of medical students. Academic Psychiatry. (2016) 40:63-8. doi: 10.1007/s40596-015-0395-9

20. de Vroege L, van den Broek A. Results of mental support for health care professionals and mental care during the COVID-19 pandemic. J Public Health (Oxf). (2021) 43:490-2. doi: 10.1093/pubmed/fdaa278

21. de Vroege L, Gribling G, van den Broek A. 'Don't forget yourself when taking care of others' - mental support for health care professionals during the COVID-19 crisis. Tijdschr Psychiatr. (2020) 62:424-6. doi: 10.1136/ebnurs-2020-103350

22. World Health Organization. Mental health and psychosocial considerations during the covid-19 outbreak [Online]. (2020). Available online at: https://www.who/int/docs/default-source/coronaviruse/mental-healthconsiderations.pdf

23. Lall MD, Gaeta TJ, Chung AS, Chinai SA, Garg M, Husain A, et al. Assessment of physician well-being, part two: beyond burnout. West J Emerg Med. (2019) 20:291-304. doi: 10.5811/westjem.2019.1.39666

24. Sandesh R, Shahid W, Dev K, Mandhan N, Shankar P, Shaikh A, et al. Impact of COVID-19 on the Mental Health of Healthcare Professionals in Pakistan. Cureus. (2020) 12:e8974. doi: 10.7759/cureus.8974

25. Bart, R., Ishak, W. W., Ganjian, S., Jaffer, K. Y., Abdelmesseh, M., Hanna, S., et al. (2018). The assessment and measurement of wellness in the clinical medical setting: a systematic review. Innov Clin Neurosci. 15:1423. doi: 10.1186/s13722-019-0164-2

26. Stanford FC, Durkin MW, Blair SN, Powell CK, Poston MB, Stallworth JR. Determining levels of physical activity in attending physicians, resident and fellow physicians and medical students in the USA. Br J Sports Med. (2012) 46:360-4. doi: 10.1136/bjsports-2011-090299
27. Weight CJ, Sellon JL, Lessard-Anderson CR, Shanafelt TD, Olsen KD, Laskowski ER. Physical activity, quality of life, and burnout among physician trainees: the effect of a team-based, incentivized exercise program. Mayo Clin Proc. (2013) 88:1435-1432. doi: 10.1016/j.mayocp.2013.09.010

28. Thomas SE, Haney MK, Pelic CM, Shaw D, Wong JG. Developing a program to promote stress resilience and self-care in first-year medical students. Can Med Educ J. (2011) 2:e32-6. doi: 10.36834/cmej.3 6548

29. Rangel EL, Castillo-Angeles M, Kisat M, Kamine TH, Askari R. Lack of routine healthcare among resident physicians in New England. J Am Coll Surg. (2020) 230:885-92. doi: 10.1016/j.jamcollsurg.2019.11.005

30. Daniel JH, Roysircar G, Abeles N, Boyd C. Individual and culturaldiversity competency: focus on the therapist. J Clin Psychol. (2004) 60:75570. doi: $10.1002 /$ jclp. 20014

31. Horvat L, Horey D, Romios P, Kis-Rigo J. Cultural competence education for health professionals. Cochrane Database Syst Rev. (2014) 5:CD009405. doi: 10.1002/14651858.CD009405.pub2

Conflict of Interest: The author declares that the research was conducted in the absence of any commercial or financial relationships that could be construed as a potential conflict of interest.

Publisher's Note: All claims expressed in this article are solely those of the authors and do not necessarily represent those of their affiliated organizations, or those of the publisher, the editors and the reviewers. Any product that may be evaluated in this article, or claim that may be made by its manufacturer, is not guaranteed or endorsed by the publisher.

Copyright (c) 2021 Vazquez Morgan. This is an open-access article distributed under the terms of the Creative Commons Attribution License (CC BY). The use, distribution or reproduction in other forums is permitted, provided the original author(s) and the copyright owner(s) are credited and that the original publication in this journal is cited, in accordance with accepted academic practice. No use, distribution or reproduction is permitted which does not comply with these terms. 